\title{
THE EFFECT OF ADMINISTRATION OF AN EQUAL DOSE OF DIFFERENT CLASSES OF PHYTOCHEMICALS ON HEME OXYGENASE-1 GENE AND PROTEIN EXPRESSION IN MICE LIVER
}

\author{
AZMAN ABDULLAH ${ }^{1 *}$, NADIA SALEM ALRAWAIQ ${ }^{1,2}$, AHMED ATIA $^{1,3}$ \\ ${ }^{1}$ Department of Pharmacology, Faculty of Medicine, Universiti Kebangsaan Malaysia Medical Centre, Jalan Yaacob Latif, Bandar Tun Razak, \\ 56000 Cheras, Kuala Lumpur, Malaysia. ${ }^{2}$ Department of Pharmacology, Faculty of Pharmacy, Sebha University, Sebha, Libya. ${ }^{3}$ Department \\ of Anesthesia and Intensive Care, Faculty of Medical Technology, Tripoli University, Tripoli, Libya.Email: manlah1969@yahoo.com
}

Received: 12 October 2018, Revised and Accepted: 27 December 2018

ABSTRACT

Objective: Heme oxygenase-1 (HO-1) is enzyme that possesses antioxidant, anti-inflammatory, and cytoprotective functions. Induction of HO-1 occurs as an adaptive and beneficial response to various injurious stimuli such as oxidative stress. This study is aimed at monitoring the effects of administration of equal doses $(50 \mathrm{mg} / \mathrm{kg}$ ) of sulforaphane (SFN), curcumin, quercetin, indole-3-carbinol, and butylated hydroxyanisole (BHA) for 14 days on the levels of liver HO-1 gene and protein expression in mice.

Method: A total of 48 adult male ICR white mice (25-30 g) were divided into eight groups: Normal control group ( $\mathrm{n}=6$ ), SFN-treated group ( $\mathrm{n}=6$ ), quercetin-treated group $(n=6)$, curcumin-treated group $(n=6)$, BHA-treated group $(n=6)$, indole-3-carbinol treated group ( $n=6)$, vehicle 1 control group $(\mathrm{n}=6)$, and vehicle 2 control group $(\mathrm{n}=6)$. All chemicals were administered intraperitoneally at a dose of $50 \mathrm{mg} / \mathrm{kg}$ for 14 days. Vehicle 1 (dimethyl sulfoxide, Tween ${ }^{\mathrm{TM}} 20$, and normal saline at a ratio of 0.05:0.1:0.85) was used to dissolve SFN, quercetin, and curcumin. Vehicle 2 (corn oil) was used to dissolve indole-3-carbinol and BHA. At day 15, the animals were sacrificed and their livers were isolated. From the liver, total RNA was extracted, reverse transcribed and subjected to quantitative real-time polymerase chain reaction to detect HO- 1 gene expression. Agarose gel electrophoresis was also performed to verify the specificity of the amplification. HO-1 protein expression was determined by Western blotting.

Results: HO-1 gene expression showed significant increase of 4.6 $\pm 0.3,3.6 \pm 0.2,3.6 \pm 0.4,3.3 \pm 0.3$, and $3.0 \pm 0.4$-fold and HO- 1 protein expression showed significant increase of $2.3 \pm 0.2,2.2 \pm 0.2,2.2 \pm 0.1,1.8 \pm 0.1$, and $1.7 \pm 0.2$-fold following treatment with $50 \mathrm{mg} / \mathrm{kg}$ of SFN, indole-3-carbinol, BHA, curcumin, and quercetin, respectively, compared to controls $(\mathrm{p}<0.05)$

Conclusion: At a dose of $50 \mathrm{mg} / \mathrm{kg}$, SFN administration for 14 days resulted in the highest induction of HO-1 gene and protein expression level in mice liver, and quercetin the lowest.

Keywords: Heme oxygenase-1, Gene expression, Protein expression, Sulforaphane, Quercetin, Curcumin, Indole-3-carbinol, Butylated hydroxyanisole, Mice, Liver.

(c) 2019 The Authors. Published by Innovare Academic Sciences Pvt Ltd. This is an open access article under the CC BY license (http://creativecommons. org/licenses/by/4. 0/) DOI: http://dx.doi.org/10.22159/ajpcr.2019.v12i3.30257

\section{INTRODUCTION}

It has been well-documented since decades ago that a diet rich in fruits and vegetables is epidemiologically proven to protect humans from developing cancer [1]. Fruits and vegetables are well known to have high antioxidant content, which promotes the removal of reactive oxygen species generated during normal oxidative metabolism and by reactions initiated by unwanted xenobiotic chemicals [2]. Some phytochemicals found in food and phenolic antioxidants are chemoprotective, in the sense that they are able to induce the expression of genes and proteins involved in cellular defense mechanism. The upregulated expression of cellular defense genes and proteins is essential for protection against oxidative/chemical stress. Some of these proteins are classified as phase II drug metabolizing enzymes, although other enzymes and antioxidant proteins are also involved. These proteins are known as phase II proteins [3]. Phase II proteins have been recognized to be modulated by the ARE/Nrf2 antioxidative signaling pathway [4,5]. Heme oxygenase-1 (HO-1) is a classic example of the phase II protein controlled by the Nrf2 signaling pathway [6]. HO- 1 is a rate-limiting enzyme that catalyzes the degradation of heme (a pro-oxidant) to carbon monoxide, biliverdin, and free iron [7]. HO-1 induction is important in terms of cellular defense mechanism due to the fact that HO-1 expression is inducible in response to various forms of cellular insult. Moreover, the end products of HO-1 catabolism exhibit antioxidative, anti-inflammatory, and antiapoptotic properties [7].
Sulforaphane (SFN), indole-3-carbinol, curcumin, and quercetin have been known to induce HO-1 activation and expression in various conditions [8-13]. However, no one has ever compared which phytochemical is the most potent in inducing the expression of HO-1 in mice liver where the liver is healthy and not subject to any disease and toxicity. Therefore, the novelty of this current study lies on the identification of the most potent HO-1 inducer among the four phytochemicals studied, for example, SFN, indole-3-carbinol, curcumin, and quercetin The most potent phytochemical could then be promoted as liver chemoprotectant, due to the fact that HO-1 has antioxidant, anti-inflammatory, and antiproliferative activities. The objective of this study was, therefore, to determine the nature and potency of HO-1 expression in mice liver induced by equal doses $(50 \mathrm{mg} / \mathrm{kg})$ of several common phytochemicals found in fruits and vegetables, i.e., SFN, curcumin, indole-3-carbinol, and quercetin. Butylated hydroxyanisole (BHA) is widely used as an antioxidant and preservative in food, food packaging, and medicines [14]. In this study, BHA was used as positive control because it is well-established to be a very potent inducer of HO-1 expression $[7,14,15]$.

\section{METHODS}

Chemicals and reagents

Forward and reverse primers used in real-time polymerase chain reaction (PCR) experiments were purchased from Vivantis Technologies 
(Oceanside, CA, USA). TRIzol Reagent was purchased from Life Technologies (Carlsbad, California, USA). iScript ${ }^{\mathrm{TM}} \mathrm{cDNA}$ synthesis kit, $\mathrm{iQ}^{\mathrm{TM}}$ SYBR $^{\circledR}$ supermix (2X) kit, and 48-well MiniOpticon ${ }^{\mathrm{TM}}$ thermal cycler were purchased from Bio-Rad (Hercules, California, USA). SFN was purchased from Santa Cruz Biotechnology (Paso Robles, California, USA). Gel Red Nucleic Acid Gel Stain $(10,000 \times$ in water) was purchased from Biotium (Hayward, California, USA). SFN was purchased from Santa Cruz Biotechnology (Paso Robles, California, USA). Curcumin, quercetin, and all other chemicals were purchased from SigmaAldrich (St. Louis, Missouri, USA). RIPA lysis buffer and anti-rabbit IgG peroxidase secondary antibody were purchased from Santa Cruz Biotechnology (Dallas, USA). Chemiluminescence Western blotting detection reagents were purchased from Amersham (Uppsala, Sweden). Nitrocellulose membrane and Ponceau S solution were purchased from Sigma-Aldrich (Seelze, Germany). HO-1 polyclonal primary antibody and $\beta$-actin rabbit polyclonal antibody were purchased from Abcam Biotechnology (Cambridge, UK). All other chemicals were purchased from Sigma-Aldrich unless otherwise stated.

\section{Animals used and their treatments}

A total of 48 male ICR white mice (25-30 g) were used in this study and were obtained from the Universiti Kebangsaan Malaysia Laboratory Animal Research Unit. The weight of mice was chosen between 25 and $30 \mathrm{~g}$ because, at that range of weight, they are categorized as adult mice [16-18]. Male mice were chosen in this study because their livers are larger than female mice. Furthermore, male mice are not subjected to estrous cycles that can complicate the pharmacological studies of rodents. Most animal pharmacology/toxicology studies have been performed with male mice due to the fact that female mice undergo estrous cycles that could create a tremendous amount of variability in experimental results [19]. The mice were kept in clean polypropylene cages in a ventilated room, with food and water available ad libitum. The mice were divided into eight groups: (1) Normal control (NC) group $(\mathrm{n}=6)$, (2) SFN-treated group $(\mathrm{n}=6),(3)$ quercetin $(\mathrm{QRC})$ treated group $(n=6)$, (4) curcumin (CUR)-treated group $(n=6)$, (5) BHAtreated group $(\mathrm{n}=6),(6)$ indole-3-carbinol (I3C) treated group $(\mathrm{n}=6)$, (7) vehicle 1 (VH1) control group ( $\mathrm{n}=6)$, and (8) vehicle $2(\mathrm{VH} 2)$ control group $(\mathrm{n}=6)$. Vehicle 1 (dimethyl sulfoxide [DMSO], Tween 20, and normal saline at a ratio of 0.05:0.1:0.85) was used to dissolve SFN, quercetin, and curcumin. Vehicle I (DMSO, Tween ${ }^{\mathrm{TM}} 20$, and normal saline in the ratio of $0.05: 0.1: 0.85$ ) were similarly administered to the vehicle 1 control group. Vehicle 2 (which is corn oil) was used to dissolve indole-3-carbinol and BHA. Vehicle 2 (corn oil) was similarly administered to the vehicle 2 control group. NC mice were given food and water ad libitum and were not subjected to any kind of treatment. Previous studies that investigated the effects of phytochemicals in mice tissues (especially the liver) had used 5, or 6 mice per each experimental group studied [9,20-24]. Eight (8) experimental groups were utilized in this present study, and since each group was assigned to include 6 mice, the total number of mice used in this study is 48 . All chemicals were administered intraperitoneally at a dose of $50 \mathrm{mg} / \mathrm{kg}$ body weight for 14 consecutive days. In previous studies [9,12,20-22,24,25], the dose of $50 \mathrm{mg} / \mathrm{kg}$ of several phytochemicals (SFN, indole-3-carbinol, quercetin, and curcumin) was effective in inducing several important antioxidant enzymes expression (including HO-1). Therefore, the phytochemical dose of $50 \mathrm{mg} / \mathrm{kg}$ was chosen in this current study because we wanted to observe which phytochemical is the most potent in inducing HO- 1 at that particular dose. At day 15, mice were sacrificed through cervical dislocation. Their livers were subsequently isolated, snapped frozen in liquid nitrogen and stored at $-80^{\circ} \mathrm{C}$ until further use. All experimental procedures involving animals were approved by the Universiti Kebangsaan Malaysia Animal Ethics Committee with the approval number: FP/FAR/2012/AZMAN/23-MAY/442-JUNE-2012-JUNE-2015.

\section{RNA extraction}

Total RNA from frozen liver tissues was isolated using TRIzol reagent, according to the manufacturer's instructions. Isopropyl alcohol (Sigma, USA) was added in each extraction step to precipitate the total RNA. The extracted total RNA pellet was then washed with $75 \%$ ethanol and air-dried at room temperature. The dried pellet containing total RNA was then dissolved in RNase-free water. The dissolved total RNA was then immediately stored at $-80^{\circ} \mathrm{C}$ after extraction. The concentration and purity of the extracted total RNA were determined by NanoDrop spectrophotometer 2000c (Thermo Scientific, USA) at a wavelength of $260 \mathrm{~nm}$ (OD260). Total RNA with RNA integrity number ranging from 7 to 10 and absorbance ratio of A260 to A280 ranging from 1.5 to 2.0 was subsequently used for cDNA synthesis.

\section{Reverse transcription}

The conversion of RNA to cDNA was achieved using the iScript ${ }^{\mathrm{TM}}$ cDNA synthesis kit (Bio-Rad, USA) and was performed according to the manufacturer's instructions. Briefly, a volume (containing $1 \mu \mathrm{g}$ ) of total RNA from each sample was added to a mixture of $4 \mu$ of $5 \times$ iScript reaction mix, $1 \mu \mathrm{l}$ of iScript ${ }^{\mathrm{TM}}$ reverse transcriptase, and a suitable volume of nuclease-free water (the final reaction mixture volume is $20 \mu \mathrm{l})$. The final reaction mixture was kept at $25^{\circ} \mathrm{C}$ for $5 \mathrm{~min}, 42^{\circ} \mathrm{C}$ for $30 \mathrm{~min}$, and heated to $85^{\circ} \mathrm{C}$ for $5 \mathrm{~min}$ in a thermocycler (TC-412, Techne, Barloworld Scientific, UK). The cDNA produced was subsequently used as a template for amplification by PCR technique.

\section{Quantification of HO-1 gene expression by quantitative real-time PCR}

Quantitative real-time PCR was performed on the MiniOpticon ${ }^{\mathrm{TM}}$ cycler (Bio-Rad, USA). The total reaction volume used was $20 \mu \mathrm{l}$, consisting of $1 \mu \mathrm{l}$ of $10 \mu \mathrm{M}$ forward primer and $1 \mu \mathrm{l}$ of $10 \mu \mathrm{M}$ reverse primer (500 $\mathrm{nM}$ final concentration of each primer), $10.0 \mu \mathrm{l}$ of $\mathrm{iQ}^{\mathrm{TM}} \mathrm{SYBR}^{\circledR}$ Green Supermix (2×) (Bio-Rad, USA), $6.0 \mu \mathrm{l}$ of nuclease-free water, and $2.0 \mu \mathrm{l}$ of cDNA. Both forward and reverse primers for the genes of interest in this study were synthesized by Vivantis Technologies (Oceanside, CA, USA). The primer sequences for our genes of interest are shown in Table 1.

The thermocycling conditions were initiated at $95^{\circ} \mathrm{C}$ for $30 \mathrm{~s}$ followed by $40 \mathrm{PCR}$ cycles of denaturation at $95^{\circ} \mathrm{C}$ for $15 \mathrm{~s}$ and annealing/extension at $60^{\circ} \mathrm{C}$ for $30 \mathrm{~s}$. At the end of each cycle, a melting curve (dissociation stage) step was initiated to determine the specificity of the primers and the purity of the final PCR product. All measurements were performed in triplicate, and no-template controls were incorporated onto the same set of PCR tubes to test for contamination by any assay reagents. Threshold cycles were determined for each gene and quantification of templates was performed according to the relative standard curve method. The relative gene expression $(\Delta \Delta \mathrm{Ct})$ technique, as defined in the Applied Biosystems User Bulletin No. 2 [26] was used to analyze the real-time PCR data. In short, the expression level of each target gene was given as relative amount normalized against GAPDH standard controls. Subsequently, agarose gel electrophoresis was performed to determine the reliability of the melting curve analysis and to confirm the size of the PCR product. Briefly, electrophoresis was performed using $1 \%$ agarose gel to separate the real-time PCR products. GelRed ${ }^{\mathrm{TM}}$ nucleic acid gel stain (Biotium, USA) was used to stain the gels for $30 \mathrm{~min}$, and the gels were subsequently de-stained in distilled water for $30 \mathrm{~min}$. Bands were then visualized under ultraviolet light using a gel documentation system (FluorChem FC2, Alpha Innotech, USA).

\section{Preparation of cytosolic protein fraction}

Liver tissue samples were homogenized in RIPA lysis buffer (which contained $10 \mu \mathrm{l}$ PMSF, $10 \mu \mathrm{l}$ sodium orthovanadate, and $10 \mu \mathrm{l}$ protease inhibitor cocktail solution per $1 \mathrm{ml}$ of $1 \times$ RIPA lysis buffer). After centrifugation, the supernatants (cytosolic fractions) were collected and their protein concentrations were determined.

Table 1: Primer sequence for GAPDH and HO-1

\begin{tabular}{ll}
\hline Gene of interest & Primer sequence \\
\hline GADPH & F: 5'-GTGGAGTCTACTGGTGTCTTCA-3' \\
& R: 5'-TTGCTGACAATCTTGAGTGAGT-3' \\
HO-1 & F: 5'-CCTCACTGGCAGGAAATCATC -3' \\
& R: 5'-TATGTAAAGCGTCTCCACGAGG -3' \\
\hline
\end{tabular}




\section{Western blotting}

The conventional western blotting procedure was performed for the immunodetection of HO-1 protein. In short, $100 \mu \mathrm{g}$ of liver protein was separated using 15\% sodium dodecyl sulfate-polyacrylamide gel electrophoresis. The proteins that were trapped within the gel were then transferred to a nitrocellulose membrane. The membrane was then incubated for $20 \mathrm{~min}$ at room temperature in blocking solution (150 mM NaCl, $3 \mathrm{mM} \mathrm{KCl,} 25 \mathrm{mM}$ Tris, 0.1\% [v/v] tween-20, and 10\% non-fat milk powder [pH 7.4]). After the blocking procedure, the membrane was sequentially incubated with the following antibodies, i.e., primary polyclonal rabbit anti-mouse HO-1 and primary polyclonal rabbit anti-mouse actin for $1 \mathrm{~h}$ at room temperature. Subsequently, incubation with a peroxidase-conjugated goat anti-rabbit IgG secondary antibody was carried out for another $1 \mathrm{~h}$ at room temperature. Protein bands were visualized using enhanced chemiluminescence method according to the manufacturer's instructions (Amersham, Uppsala, Sweden). The intensity of the protein bands was quantified, relative to the signals obtained for actin, using ImageJ software.

\section{Statistical analysis}

Data are presented as mean \pm standard error of the mean. Significant differences between mean values of multiple groups were determined using one-way ANOVA and student's $t$-test. Statistical analysis was conducted using the SPSS software version 22. The result was considered statistically significant when $\mathrm{p}<0.05$.

\section{RESULTS}

The effects of administration of equal doses of SFN, indole-3-carbinol, curcumin, and quercetin on mice liver HO-1 gene expression

The gene expression of liver HO-1 showed significant increase of $4.6 \pm 0.3,3.6 \pm 0.2,3.3 \pm 0.3$, and $3.0 \pm 0.4$-fold following treatment of mice with $50 \mathrm{mg} / \mathrm{kg} \mathrm{SFN}$, indole-3-carbinol, curcumin, and quercetin, respectively, for 14 days, as compared to controls $(\mathrm{p}<0.05)$ (Fig. 1). Therefore, in terms of liver HO-1 gene expression, the inducing potency of the phytochemicals was in the order of SFN > indole-3-carbinol > curcumin $>$ quercetin. BHA as the positive control significantly induced the gene expression of liver HO- 1 by $3.6 \pm 0.4$-fold $(p<0.05)$.

The effects of administration of equal doses of SFN, indole-3carbinol, curcumin, and quercetin on mice liver HO-1 protein expression

The protein expression of liver HO- 1 showed significant increase of $2.3 \pm 0.2,2.2 \pm 0.2,1.8 \pm 0.1$, and $1.7 \pm 0.2$-fold following treatment of mice with $50 \mathrm{mg} / \mathrm{kg} \mathrm{SFN}$, indole-3-carbinol, curcumin, and quercetin, respectively, for 14 days, as compared to controls $(\mathrm{p}<0.05)$ (Fig. 2). Therefore, in terms of liver HO-1 protein expression, the inducing potency of the phytochemicals was in the order of SFN > indole-3carbinol $>$ curcumin $>$ quercetin. BHA as the positive control significantly induced the protein expression of liver HO- 1 by $2.2 \pm 0.1$-fold ( $\mathrm{p}<0.05$ ). As observed, the pattern of the results for liver HO-1 protein expression was agreeable with those of liver HO-1 gene expression (compare Figs. 1 and 2).

\section{DISCUSSION}

Excess heme in the body is one of the factors that could result in increased oxidative stress. Degradation of heme by HO- 1 and the production of heme degradation compounds are, therefore, important measures to decrease the level of oxidative stress, inflammation, and cytotoxic reactions in the body [27]. Proinflammatory cytokines such as tumor necrosis factor $\alpha$, transforming growth factor $\beta$, and interleukin-1 $\beta$ had been found to increase HO-1 activation, which suggested that the body was responding toward the injurious stimuli subjected toward it [28]. HO-1 knockout mice have been discovered to possess enlarged spleen and increased incidence of hepatic lesions due to the occurrence of unchallenged chronic inflammatory process [29]. Humans with HO-1 deficiency have been shown to be susceptible to oxidative stress and inflammation which will eventually lead to severe endothelial

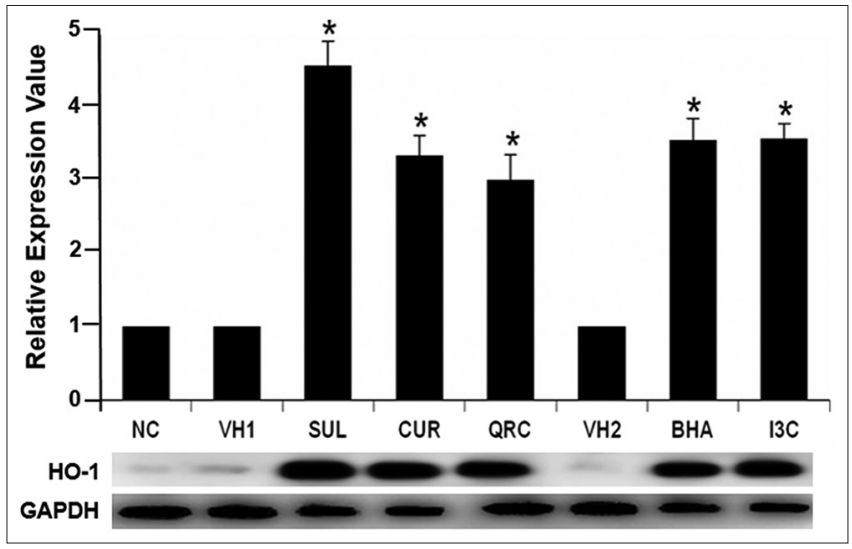

Fig. 1: Effects of intraperitoneal administration of $50 \mathrm{mg} / \mathrm{kg}$ sulforaphane, curcumin, quercetin, indole-3-carbinol, and butylated hydroxyanisole for 14 days on HO-1 gene expression in the livers of mice using real-time PCR (qPCR). GAPDH was designated as the reference gene. Data were represented as mean \pm SEM of six experiments, $n=6 .{ }^{*} p<0.05$ compared to all control groups (normal control, vehicle 1 control, and vehicle 2 control groups). NC: Normal control, VH1: Vehicle control 1 group (vehicle 1 treated group), VH2: Vehicle 2 control group (vehicle 2 treated group), SUL: Sulforaphane-treated group, CUR: Curcumintreated group, QRC: Quercetin-treated group, BHA: Butylated

hydroxyanisole-treated group, I3C: Indole 3 carbinol-treated group. Agarose gel electrophoresis was also performed to confirm the results of qPCR experiments

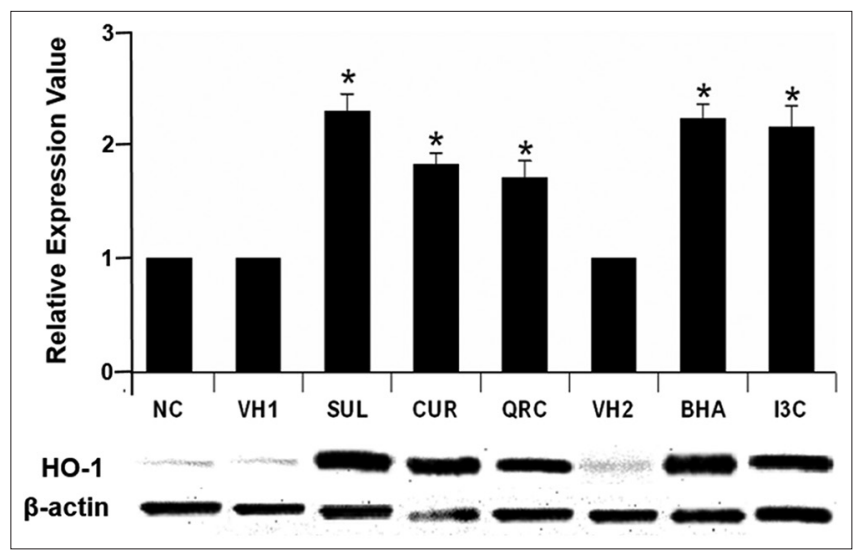

Fig. 2: Effects of intraperitoneal administration of $50 \mathrm{mg} / \mathrm{kg}$ sulforaphane, curcumin, quercetin, indole-3-carbinol, and butylated hydroxyanisole for 14 days on $\mathrm{H0}-1$ protein expression in the livers of mice using western immunoblotting. Data were represented as mean \pm SEM of six experiments, $n=6$. ${ }^{*} p<0.05$ compared to all control groups (normal control, vehicle 1 control, and vehicle 2 control groups). NC: Normal control, VH1: Vehicle control 1 group (vehicle 1 treated group), VH2: Vehicle 2 control group (vehicle 2 treated group), SUL: Sulforaphane-treated group, CUR: Curcumin-treated group, QRC: Quercetin-treated group, BHA: Butylated hydroxyanisole-treated group, I3C: Indole 3 carbinol-treated group. $\beta$-actin served as the housekeeping protein. The graph represents the relative amount of H0-1 band density normalized to $\beta$-actin

damage [30]. Induction of HO-1 has been shown to prevent hepatocyte damage due to oxidative stress [31]. Many of the classical HO-1 triggers have been shown to induce HO-1 expression through nuclear factor E2-related factor 2 (Nrf2) binding to the antioxidant response element in the promoter region of HO-1 gene [32]. Experiments conducted on Nrf2-deficient mice showed the importance of Nrf2 in stress-dependent 
induction of HO-1 because $\mathrm{HO}-1$ was found to be less inducible in such mice [33].

Great importance has been emphasized on the consumption of plantderived natural compounds such as curcumin, SFN, polyphenols, flavonoids, and isothiocyanates as potential chemopreventive agents. Various studies done on these compounds have repeatedly shown that they possess anticancer properties. Therefore, the utilization of these compounds as natural anticancer therapies should be thoroughly explored [34]. One of the research areas that need to be explored is the extent to which these phytochemicals induce antioxidant enzymes in vivo. HO-1 is a unique enzyme with potent anti-inflammatory, antioxidative, and anti-proliferative effects. Furthermore, HO-1 has been postulated to be important in cellular protection. Increasing the expression of HO-1 could be an effective therapeutic intervention to combat certain ailments. Therefore, inducing HO-1 expression by pharmacological means could increase the antioxidant capacity of numerous types of cells [35]. Phytochemicals such as SFN, curcumin, and quercetin have been shown to induce HO-1 expression in liver cells (hepatocytes) as well as in the liver itself [10,36,37]. However, what is not known is which of these phytochemicals are the most potent in inducing HO-1 expression. The results of our study clearly showed that SFN is the most potent in terms of inducing HO-1 expression in mice liver, followed by indole-3-carbinol, curcumin, and quercetin. Therefore, increased consumption of SFN rich food such as broccoli in humans could be beneficial in terms of general health and cancer chemoprevention strategy. At present, not much can be done to prevent liver cell damage and degeneration. Therefore, the induction of HO-1 by safer means such as supplementation with natural products may be an effective strategy to prevent liver carcinogenesis and other liver diseases such as alcohol-dependent liver damage, liver ischemia/ reperfusion injury, and liver fibrosis [8,38-40]. The results of this study indicated that SFN, quercetin, and curcumin were able to induce HO-1 gene expression in mice liver. Therefore, it can be hypothesized that these chemicals induce HO-1 expression in the liver as part of their chemoprevention/chemoprotective effects; however, more studies are needed to confirm this.

Previous studies have shown that SFN, curcumin, and quercetin were able to induce HO-1 activation and expression when the liver was subjected to oxidative and/or chemical stress, for example, ethanol, paracetamol, and carbon tetrachloride (CCl4)-induced liver toxicity [8-11,13]. However, none of those studies had attempted to find out which phytochemical is the most potent in inducing liver HO-1 expression in normal unstressed conditions. Therefore, we undertook this study to find out which phytochemical is the most potent in inducing liver HO-1 expression in normal wild-type unstressed white mice. This is because stressful conditions, for example, liver injury/toxicity might mask/inhibit the natural capacity of the liver to induce HO-1 expression. As our results suggested, in the unstressed healthy liver, the most potent inducer of liver HO-1 expression is SFN.

There are several limitations associated with this study. Only four phytochemicals were utilized in this research. Other phytochemicals which are not tested could prove to be more potent than SFN. Only one dose of phytochemicals $(50 \mathrm{mg} / \mathrm{kg}$ ) was administered. Higher doses of phytochemicals could result in different HO-1 induction levels and patterns. Only healthy mice were used in this experiment. The HO-1 induction response and pattern might be different if the mice are challenged with liver disease or liver toxicity. Only mice were used in this study. Results (induction response and pattern) obtained using other rodents (e.g., rats) and species (e.g., humans) might be different from mice. Longer duration of treatment might also result in different levels and patterns of HO-1 induction. In recent years there has been tremendous development of various novel drug delivery systems for herbal drugs, which could deliver the herbal preparations inside the body with higher bioavailability. Liposomes have been used as novel carriers for numerous phytochemicals since it could entrap both hydrophilic and lipophilic drugs with great success [41]. Therefore, for
SFN (or other phytochemicals) to have greater bioavailability in the body, SFN should be delivered using liposomes (or other newer and effective delivery systems) so that maximal therapeutic effects could be elicited.

\section{CONCLUSION}

According to the findings of this study, at a dose of $50 \mathrm{mg} / \mathrm{kg}$ for 14 days, administration of SFN has the most significant impact on the induction of HO-1 expression in the liver of mice, followed by indole-3-carbinol, curcumin, and quercetin. SFN can be found abundantly in cruciferous vegetables such as broccoli. HO-1 is transcriptionally upregulated by a large variety of stimuli, for example, heme, oxidative stress, signaling proteins, cytokines, and organic chemicals. Therefore, the induction of HO-1 by pharmacological means, preferentially through supplementation of various forms of natural products, offers a potential new therapeutic target for liver degenerative diseases. In this respect, for some very promising chemoprotective phytochemicals such as SFN, the recommended therapeutic dose which is effective in the prevention or treatment of liver diseases should be aggressively investigated. Results obtained from this study further strengthen the importance of consuming more fruits and vegetables which could potentially prove to be an affordable chemoprotective measure in the long run. Further studies should be done to conclusively support this strategy.

\section{AUTHOR'S CONTRIBUTIONS}

Azman Abdullah is the principal investigator of the research project and is responsible for the design of the study and in securing funding for the study. He is also responsible for critically editing and revising the manuscript and the submission of the manuscript to this journal. Nadia Salem Alrawaiq is the main investigator of the research project and performed most of the laboratory work and data analysis and is also involved in drafting the initial version of the manuscript. Ahmed Atia is a coinvestigator on the research project and is also involved in performing some of the laboratory work and data analysis.

\section{ACKNOWLEDGMENTS}

The authors would like to gratefully acknowledge the Department of Pharmacology, Faculty of Medicine, Universiti Kebangsaan Malaysia, for providing the facilities and resources to conduct this research. The authors are grateful to the Ministry of Higher Education Malaysia for the main funding of this research project (Code Project No: FRGS/1/2012/ SKK03/UKM/02/2). The authors would also like to thank Universiti Kebangsaan Malaysia for the additional financial support towards this research project (Code Project No: UKM-GUP-2011-297).

\section{CONFLICTS OF INTEREST}

All authors declare that there are no conflicts of interest.

\section{REFERENCES}

1. Stan SD, Kar S, Stoner GD, Singh SV. Bioactive food components and cancer risk reduction. J Cell Biochem 2008;104:339-56.

2. Abuajah CI, Ogbonna AC, Osuji CM. Functional components and medicinal properties of food: A review. J Food Sci Technol 2015;52:2522-9.

3. Keum YS. Regulation of nrf2-mediated phase II detoxification and anti-oxidant genes. Biomol Ther (Seoul) 2012;20:144-51.

4. Kitteringham NR, Abdullah A, Walsh J, Randle L, Jenkins RE, Sison R, et al. Proteomic analysis of nrf2 deficient transgenic mice reveals cellular defence and lipid metabolism as primary nrf2-dependent pathways in the liver. J Proteomics 2010;73:1612-31.

5. Abdullah A, Kitteringham NR, Jenkins RE, Goldring C, Higgins L, Yamamoto $\mathrm{M}$, et al. Analysis of the role of nrf2 in the expression of liver proteins in mice using two-dimensional gel-based proteomics. Pharmacol Rep 2012;64:680-97.

6. He $\mathrm{CH}$, Gong $\mathrm{P}, \mathrm{Hu} \mathrm{B}$, Stewart D, Choi ME, Choi AM, et al. Identification of activating transcription factor 4 (ATF4) as an nrf2interacting protein. Implication for heme oxygenase-1 gene regulation. J Biol Chem 2001;276:20858-65. 
7. Keum YS, Han YH, Liew C, Kim JH, Xu C, Yuan X, et al. Induction of heme oxygenase-1 (HO-1) and $\mathrm{NAD}[\mathrm{P}] \mathrm{H}$ : Quinone oxidoreductase 1 (NQO1) by a phenolic antioxidant, butylated hydroxyanisole (BHA) and its metabolite, tert-butylhydroquinone (tBHQ) in primary-cultured human and rat hepatocytes. Pharm Res 2006;23:2586-94.

8. Nussler AK, Hao L, Knobeloch D, Yao P, Nussler NC, Wang Z, et al. Protective role of HO-1 for alcohol-dependent liver damage. Dig Dis 2010;28:792-8.

9. Domitrović R, Jakovac H, Vasiljev Marchesi V, Vladimir-Knežević S, Cvijanović O, Tadić Z, et al. Differential hepatoprotective mechanisms of rutin and quercetin in $\mathrm{CCl}(4)$-intoxicated $\mathrm{BALB} / \mathrm{cN}$ mice. Acta Pharmacol Sin 2012;33:1260-70.

10. Noh JR, Kim YH, Hwang JH, Choi DH, Kim KS, Oh WK, et al. Sulforaphane protects against acetaminophen-induced hepatotoxicity. Food Chem Toxicol 2015;80:193-200.

11. Ji LL, Sheng YC, Zheng ZY, Shi L, Wang ZT. The involvement of p62keap1-nrf2 antioxidative signaling pathway and JNK in the protection of natural flavonoid quercetin against hepatotoxicity. Free Radic Biol Med 2015;85:12-23.

12. Hajra S, Patra AR, Basu A, Bhattacharya S. Prevention of doxorubicin (DOX)-induced genotoxicity and cardiotoxicity: Effect of plant derived small molecule indole-3-carbinol (I3C) on oxidative stress and inflammation. Biomed Pharmacother 2018;101:228-43.

13. Liu S, Tian L, Chai G, Wen B, Wang B. Targeting heme oxygenase-1 by quercetin ameliorates alcohol-induced acute liver injury via inhibiting NLRP3 inflammasome activation. Food Funct 2018:9:4184-93.

14. Luo L, Chen Y, Wu D, Shou J, Wang S, Ye J, et al. Butylated hydroxyanisole induces distinct expression patterns of nrf2 and detoxification enzymes in the liver and small intestine of C57BL/6 mice. Toxicol Appl Pharmacol 2015;288:339-48.

15. Liu XM, Azam MA, Peyton KJ, Ensenat D, Keswani AN, Wang H, et al. Butylated hydroxyanisole stimulates heme oxygenase-1 gene expression and inhibits neointima formation in rat arteries. Cardiovasc Res 2007:74:169-79.

16. Sharma A, Sharma MK, Kumar M. Protective effect of Mentha piperita against arsenic-induced toxicity in liver of swiss albino mice. Basic Clin Pharmacol Toxicol 2007;100:249-57.

17. Sanghamitra S, Hazra J, Upadhyay SN, Singh RK, Amal RC. Arsenic induced toxicity on testicular tissue of mice. Indian J Physiol Pharmacol 2008;52:84-90.

18. Sharma A, Sharma MK, Kumar M. Modulatory role of emblica officinalis fruit extract against arsenic induced oxidative stress in Swiss albino mice. Chem Biol Interact 2009;180:20-30.

19. Roehr B. Why sex matters in mouse models. Sci 2007;21:49.

20. Molina MF, Sanchez-Reus I, Iglesias I, Benedi J. Quercetin, a flavonoid antioxidant, prevents and protects against ethanol-induced oxidative stress in mouse liver. Biol Pharm Bull 2003;26:1398-402.

21. Innamorato NG, Rojo AI, García-Yagüe AJ, Yamamoto M, de Ceballos ML, Cuadrado A, et al. The transcription factor nrf2 is a therapeutic target against brain inflammation. J Immunol 2008;181:680-9.

22. Girish C, Koner BC, Jayanthi S, Ramachandra Rao K, Rajesh B, Pradhan SC, et al. Hepatoprotective activity of picroliv, curcumin and ellagic acid compared to silymarin on paracetamol induced liver toxicity in mice. Fundam Clin Pharmacol 2009;23:735-45.

23. Priya DK, Gayathri R, Gunassekaran GR, Sakthisekaran D. Protective role of sulforaphane against oxidative stress mediated mitochondrial dysfunction induced by benzo(a)pyrene in female Swiss albino mice.
Pulm Pharmacol Ther 2011;24:110-7.

24. Oh CJ, Kim JY, Min AK, Park KG, Harris RA, Kim HJ, et al. Sulforaphane attenuates hepatic fibrosis via NF-E2-related factor 2 -mediated inhibition of transforming growth factor- $\beta /$ Smad signaling. Free Radic Biol Med 2012;52:671-82.

25. Heeba GH, Mahmoud ME, El Hanafy AA. Anti-inflammatory potential of curcumin and quercetin in rats: Role of oxidative stress, heme oxygenase-1 and TNF- $\alpha$. Toxicol Ind Health 2014;30:551-60.

26. Livak KJ, Schmittgen TD. Analysis of relative gene expression data using real-time quantitative PCR and the 2(-delta delta $\mathrm{C}(\mathrm{T})$ ) method. Methods 2001;25:402-8.

27. Chang M, Xue J, Sharma V, Habtezion A. Protective role of hemeoxygenase-1 in gastrointestinal diseases. Cell Mol Life Sci 2015;72:1161-73.

28. Kandavelu S, Somasundram PC, John B, Rajendran R. Pro-inflammatory cytokines elicit inflammatory response in blood leukocytes of post dialytic chronic renal patients through heme oxygenase-1 activation. Int J Pharm Pharm Sci 2014;6:111-5.

29. Choi JH, Kim DW, Yun N, Choi JS, Islam MN, Kim YS, et al. Protective effects of hyperoside against carbon tetrachloride-induced liver damage in mice. J Nat Prod 2011;74:1055-60.

30. Eipel C, Hirschmann M, Abshagen K, Menger MD, Vollmar B. Local interaction of apoptotic hepatocytes and kupffer cells in a rat model of systemic endotoxemia. Hepatol Res 2007;37:863-71.

31. Brockmann JG, August C, Wolters HH, Hömme R, Palmes D, Baba H, et al. Sequence of reperfusion influences ischemia/reperfusion injury and primary graft function following porcine liver transplantation. Liver Transpl 2005;11:1214-22.

32. Martin D, Rojo AI, Salinas M, Diaz R, Gallardo G, Alam J, et al. Regulation of heme oxygenase-1 expression through the phosphatidylinositol 3-kinase/Akt pathway and the nrf2 transcription factor in response to the antioxidant phytochemical carnosol. J Biol Chem 2004;279:8919-29.

33. Cho HY, Jedlicka AE, Reddy SP, Kensler TW, Yamamoto M, Zhang LY, et al. Role of NRF2 in protection against hyperoxic lung injury in mice. Am J Respir Cell Mol Biol 2002;26:175-82.

34. Saka S, Singh AN, Sharma N. Potential anti-cancer superfoods: A minireview. Int J Curr Pharm Res 2016;8:19-21.

35. Islam MT, De Alencar MV, Paz MF, Matos LA, Sousa JM, MeloCavalcante AA. Coffee: A health fuel-blot popular drinking. Int J Pharm Pharm Sci 2016;8:1-7.

36. Yao P, Nussler A, Liu L, Hao L, Song F, Schirmeier A, et al. Quercetin protects human hepatocytes from ethanol-derived oxidative stress by inducing heme oxygenase-1 via the MAPK/Nrf2 pathways. J Hepatol 2007:47:253-61.

37. Bao W, Li K, Rong S, Yao P, Hao L, Ying C, et al. Curcumin alleviates ethanol-induced hepatocytes oxidative damage involving heme oxygenase-1 induction. J Ethnopharmacol 2010;128:549-53

38. Liu S, Hou W, Yao P, Li N, Zhang B, Hao L, et al. Heme oxygenase-1 mediates the protective role of quercetin against ethanol-induced rat hepatocytes oxidative damage. Toxicol In Vitro 2012;26:74-80.

39. Sass G, Barikbin R, Tiegs G. The multiple functions of heme oxygenase-1 in the liver. Z Gastroenterol 2012;50:34-40.

40. Liu B, Qian JM. Cytoprotective role of heme oxygenase-1 in liver ischemia reperfusion injury. Int J Clin Exp Med 2015;8:19867-73.

41. Khan YY, Suvarna V. Liposomes containg phytochemicals for cancer treatment - An update. Int J Curr Pharm Res 2017;9:20-4. 